\title{
Estimaciones acerca de la salud de poblaciones que ocuparon las Sierras Centrales y Planicies Orientales (Córdoba, Argentina) en el Holoceno Tardío: una aproximación desde la antropología dental)
}

\author{
Antropología Biológica
}

Claudina V. González* y Mariana Fabra**

\begin{abstract}
*Museo de Antropología, Facultad de Filosofía y Humanidades, Universidad Nacional de Córdoba. E-mail: cvictoriagonzalez22@hotmail.com

**CONICET, Museo de Antropología, Facultad de Filosofía y Humanidades, Universidad Nacional de Córdoba. E-mail: marianafabra@gmail.com
\end{abstract}

\begin{abstract}
Resumen
El objetivo de este trabajo es analizar desde una perspectiva bioarqueológica las condiciones generales de salud de las poblaciones humanas que ocuparon la región austral de las Sierras Pampeanas en el Holoceno tardío (ca. 2500-400 años A.P.), particularmente a través del estudio de bioindicadores dentales tales como hipoplasias del esmalte dental, abscesos y pérdidas dentales ante mortem. Se analizó una muestra de 80 individuos adultos de ambos sexos, procedentes de 48 sitios de toda la región. Se calcularon prevalencias por sexo, edad, cronología -Holoceno tardío inicial (ca. 2500-1500 años AP.) y final (ca.1500-400 años AP)-, así como sub-regiones geográficas - Sierras Chicas, Noreste, Noroeste, Llanura extraserrana, Sur y Traslasierra-. Posteriormente, se evaluó si las diferencias observadas eran significativas o no, mediante la aplicación del test de Chi-cuadrado (X2). Los resultados indican que las poblaciones asentadas en la región hacia momentos finales del Holoceno tardío habrían sufrido un deterioro en las condiciones generales de salud, principalmente los individuos adultos jóvenes y medios de toda el área, siendo mayor la intensidad en las sub regiones Noreste y Traslasierra.
\end{abstract}

Palabras clave: bioindicadores dentales; salud; región austral de las Sierras Pampeanas; Bioarqueología.

Estimating Late Holocene health from Cordoba's Central Highlands end Eastern Lowland populations (Argentina). A dental anthropology approach

\begin{abstract}
The aim of this work is to study, from a bioarchaeological perspective, the health conditions of the populations that inhabited the southern portion of the Sierras Pampeanas region (Córdoba province) by the Late Holocene (ca. 2500400 years BP), through the analysis of three non-specific indicators of stress and infectious diseases: hypoplasia of dental enamel, abscesses, and antemortem teeth loss. The sample is composed by 80 adult individuals from 48 archaeological sites. We calculated the relative prevalence of those variables by sex, age, geographic sub regions, and chronological periods. Possible significant differences between subsamples were tested using the Chi-square test. Results suggest that human populations of the Sierras Centrales suffered deterioration in health conditions at later late Holocene, principally among young and middle age adults. This can be observed in the whole region but is more marked in the Northeast and Traslasierra sub regions.
\end{abstract}

Keywords: dental bioindicators; health; southern Sierras Pampeanas region; Bioarchaeology.

En el estado actual del conocimiento sobre las poblaciones prehispánicas del sector austral de las Sierras Pampeanas y llanuras adyacentes existen diversas problemáticas aún por resolver, referidas a la dinámica evolutiva y adaptativa de las poblaciones humanas en el pasado. Una cuestión no abordada a escala regional es la de los modos de vida desarrollados por las poblaciones que se asentaron en esta región a lo largo del Holoceno desde una perspectiva bioarqueológica, es decir, que priorice el estudio de las condiciones de salud de las poblaciones, así como cambios o continuidades en la dieta para distintos momentos del Holoceno, entre otros temas.

Las poblaciones que habitaron esta región -definida desde la Arqueología como Sierras Centrales (González y Pérez 2007)- experimentaron, desde comienzos del Holoceno temprano hasta la llegada de los españoles en el siglo XVI, diversos cambios y transformaciones en 
sus modos de vida. Tomando como punto de partida la evidencia arqueológica, se señala la permanencia de estrategias de subsistencia basadas en la caza y en la recolección, desde los primeros grupos que ocuparon la región, hace aproximadamente 11000 años hasta mediados de la era cristiana (Bonnin y Laguens 2000; Laguens y Bonnin 2009). Estas estrategias facilitaron la ocupación efectiva de territorios y el mantenimiento de formas económicas y tecnológicas. La incorporación de la agricultura y de la cerámica se habría producido aproximadamente 1500 años AP. En general, se sostiene que el desarrollo y perfeccionamiento de prácticas agrícolas implicó para las poblaciones humanas una serie de ajustes, modificaciones, reinterpretaciones y creaciones en varios aspectos de la vida de los pueblos. Los indígenas de las Sierras Centrales lograron establecer una forma económica de carácter mixto, donde la agricultura se incorporó como una estrategia de subsistencia más junto a las tradicionales de caza y recolección, organizadas en torno al aprovechamiento de las diferencias ambientales, regionales y locales, con miras a asegurar un aprovisionamiento anual más o menos constante (Laguens y Bonnin 2009). Se trató de un proceso generalizado de diversificación e intensificación en todos los aspectos de la vida de estas poblaciones, que se manifestaría como procesos locales de diferenciación regional en diversos aspectos de la vida de las personas, incluyendo las prácticas mortuorias (Fabra et al. 2009).

Laguens y Bonnin (2009) destacan que para los momentos previos a la conquista española la población de la región austral de las Sierras Pampeanas había alcanzado los límites de la capacidad de sustento del ambiente, y que las sociedades se hallarían en una situación de crisis y conflicto, que habría abarcado no sólo sus medios de subsistencia, sino también su forma de organización y las estructuras tradicionales de poder y autoridad. Estaría en marcha un proceso incipiente de reestructuración de las jerarquías políticas, de las alianzas entre los pueblos y de intensificación de la autoridad a través del ritual, que no logró prosperar por el cambio cultural forzado que significó la imposición del régimen colonial. Se estima que antes de la conquista, se había alcanzado una densidad poblacional de 6,53 habitantes por $\mathrm{km}^{2}$, lo que por cierto resulta un valor bastante alto, ya que correspondería a algo más de 5000 habitantes sólo para el valle de Copacabana. Proyectando estos datos para el resto de los valles, se estimó una población de 30000 habitantes para toda la región (Laguens 1999).

Las fuentes etnohistóricas ${ }^{1}$ señalan también cómo las estructuras políticas estaban en procesos de separación o fisión. Cuando una población alcanza el máximo del sustento que le puede brindar el ambiente, los grupos pueden adoptar -como estrategia adaptativa- la fisión en

\footnotetext{
1 La crónica de Sotelo de Narváez de 1583, las cartas del padre Barzana de 1594, y la Relación Anónima de 1573 entre otras (citados en Laguens y Bonnin 2009).
}

grupos menores, pero continúan manteniendo relaciones, muchas de las cuales se podían reforzar a través de prácticas rituales como las juntas o la recolección de frutos silvestres, o incluso en situaciones de conflicto. A través de algunos testimonios recogidos de las fuentes documentales se puede percibir que estos procesos se habían producido con anterioridad a la llegada de los españoles.

En este contexto, el objetivo del presente trabajo es contribuir desde una perspectiva bioarqueológica al conocimiento de los modos de vida, particularmente las condiciones de salud de las poblaciones humanas que ocuparon la región austral de las Sierras Pampeanas en el Holoceno tardío (ca.2500-400 años AP.-) a partir del estudio de bioindicadores dentales, y discutir los resultados obtenidos con la información arqueológica, isotópica y cronológica que se posee para la región. Para ello, se estimará la frecuencia de indicadores óseos y dentales de estrés nutricional y/o metabólico- sistémico, tales como líneas de hipoplasia del esmalte dental, así como patologías de origen infeccioso, y se los relacionará con cambios en las condiciones de salud de las poblaciones. Se evaluará la prevalencia de patrones diferenciales por sexo y edad en todos los procesos patológicos, fisiológicos y metabólicos considerados, prestando particular atención a la cronología de su ocurrencia.

Como hipótesis de trabajo se propone que entre los entre los siglos XII y XV de la era cristiana, las poblaciones que habitaron esta región se habrían visto sometidas a una serie de cambios o presiones -de tipo ambiental, demográfico y/o social- los cuales habrían impactado negativamente en el modo y las condiciones de vida de las sociedades indígenas, generando un desmejoramiento de las condiciones generales de salud, en comparación con momentos previos. Se espera encontrar en el registro dental un incremento de los indicadores de estrés metabólico (hipoplasia del esmalte dental) y mayor ocurrencia de enfermedades pulpo-alveolares (pérdidas dentales ante mortem, abscesos) en momentos previos a la conquista española.

\section{Área de estudio}

Desde un punto de vista geográfico, nuestra área de estudio se ubica en la región austral de las Sierras Pampeanas, entre los 30 y 35 grados de latitud Sur y 62 y 66 grados de longitud Oeste, abarcando los cordones montañosos de las provincias de Córdoba y San Luis, así como las llanuras orientales y occidentales aledañas.

Desde el punto de vista fisiográfico, la provincia de Córdoba está caracterizada por dos paisajes contrastantes: las sierras y las planicies, representativas de las provincias del Espinal y Pampeana respectivamente, dentro del dominio Chaqueño. El emplazamiento subtropical de la región impone un período seco en el invierno y precipitaciones 
en el verano (Capitanelli 1979). Las primeras conforman, junto con las sierras de San Luis, el denominado sistema de las Sierras Pampeanas, y las segundas se integran a la llanura pampeana como unidad geomórfica.

\section{Variaciones paleoclimáticas}

Las condiciones climáticas de la región han sufrido variaciones a través del tiempo, y éstas seguramente han influido en la vida de las poblaciones prehistóricas durante el Holoceno. Los registros paleontológicos (Leonardi 1961) y paleoclimáticos realizados sobre sedimentos lacustres (Piovano 2002) nos informan sobre estos cambios, y son una importante fuente de información durante los últimos 10000 años.

A comienzos del Holoceno tardío, aproximadamente hace 3000 AP., se produce un cambio abrupto de las condiciones climáticas: en sus comienzos, el clima presentaba condiciones más cálidas y húmedas que en momentos precedentes y fue reemplazado por un episodio cálido y semiárido o árido, con temperaturas más elevadas que las actuales, y con condiciones de déficit de agua, las que ocasionaron erosión en los suelos, déficit de agua y disminución del caudal de los grandes ríos, retracción de paleolagos, formación de las Salinas Grandes, y transformación en pantano de la Laguna Mar Chiquita, con algunos espejos de agua en su interior (Carignano 1997). Estas condiciones habrían durado aproximadamente hasta cerca del año 1000 d.C., cuando este evento fue siendo reemplazado por otro caracterizado por un clima más húmedo.

Diversos indicadores sugieren que para el período 1100-1400 d.C. (Iriondo 1999) se produjo un intervalo caracterizado por condiciones climáticas húmedas, con un régimen pluvial más húmedo o similar al actual (Carignano 1997), denominado a nivel mundial "Anomalía Climática Medieval". La evidencia arqueológica sugiere, para diversos sitios de la región, condiciones climáticas más benignas, con un marcado incremento de la sustentabilidad del ambiente (Laguens y Bonnin 1987). Este intervalo corresponde a un mejoramiento climático en la región central del país, registrado por un incipiente desarrollo del suelo, expansión de los sistemas lacustres y fluviales y formación de pantanos en las zonas bajas. (Carignano 1997).

Otro evento, conocido a nivel mundial como la "Pequeña Edad de Hielo", se produce desde fines del siglo XIV hasta mediados del siglo XIX y consistió, según la evidencia disponible, en un deterioro climático hacia condiciones de mayor aridez y frío que las observadas en el presente. En la región central del actual territorio argentino este episodio no fue homogéneo, estuvo formado por dos pulsos fríos, separados por un período intermedio de condiciones climáticas más benignas, similares a las actuales, e incluso un poco más húmedas (Cioccale 1999). El primer pulso se produce entre comienzos del siglo $\mathrm{XV}$ y finales del siglo XVI, coincidiendo según el registro arqueológico disponible para esta región con un desmejoramiento en las condiciones del sistema indígena caracterizado por stress poblacional producido por una disminución en la sustentabilidad ambiental (Laguens 1993). El segundo pulso se habría producido desde comienzos del siglo XVIII y XIX: la información histórica revela importantes déficit de precipitaciones durante el siglo XVIII y comienzos del siglo XIX, con grandes oscilaciones interanuales $y$ marcados ciclos de sequía y humedad que afectaron principalmente a la región norte -sur de Santiago del Estero, norte de Córdoba. En cuanto a la fitogeografía, se produce una notable disminución en la flora, reemplazo de especies del Chaco Oriental por asociaciones del Chaco Occidental y el Monte, en equilibrio con condiciones ambientales más secas (Bonnin et al. 1987). Se reactivan procesos erosivos en diversas áreas, se retrae la Laguna Mar Chiquita con niveles menores a los registrados en el siglo $X X$ y se forman salares que perduran hasta la actualidad en el Noroeste de la provincia. Este cambio climático modificó el paisaje y la distribución de la vegetación, y fue uno de los principales factores que reguló las actividades humanas durante los últimos 1000 años (Cioccale 1999).

\section{Materiales y métodos}

\section{Las muestras}

En este trabajo se analiza la dentición permanente de 80 individuos adultos (1102 piezas dentales y 1944 alvéolos observados), provenientes de 48 sitios arqueológicos localizados en distintas regiones de la actual provincia de Córdoba - Noreste, Noroeste, Traslasierra, Sierras Chicas, Sur y Llanura Extraserrana (Figura 1, Tabla 1). Las muestras corresponden a 47 individuos adultos de sexo masculino y 33 de sexo femenino. Para la selección de las muestras se tuvo en cuenta la presencia de más del $50 \%$ de la dentición y el hueso alveolar en cada individuo.

\section{Bioindicadores dentales}

Como parte del registro arqueológico, el material dental es uno de los elementos mejor conservados a través del tiempo, que puede brindar valiosa información sobre cambios en la dieta, densidad demográfica, escasez de ciertos recursos y competencia por los mismos, fenómenos que pueden estar íntimamente asociados a procesos de cambio social. El particular grado de dureza de las piezas dentarias derivado de sus características físicas y químicas les ha conferido una baja susceptibilidad a la degradación postdepositacional en los contextos arqueológicos, permitiendo en muchos casos una conservación diferencial respecto al resto del esqueleto (Hillson 1996).

Los estudios de bioindicadores dentales -tales como 


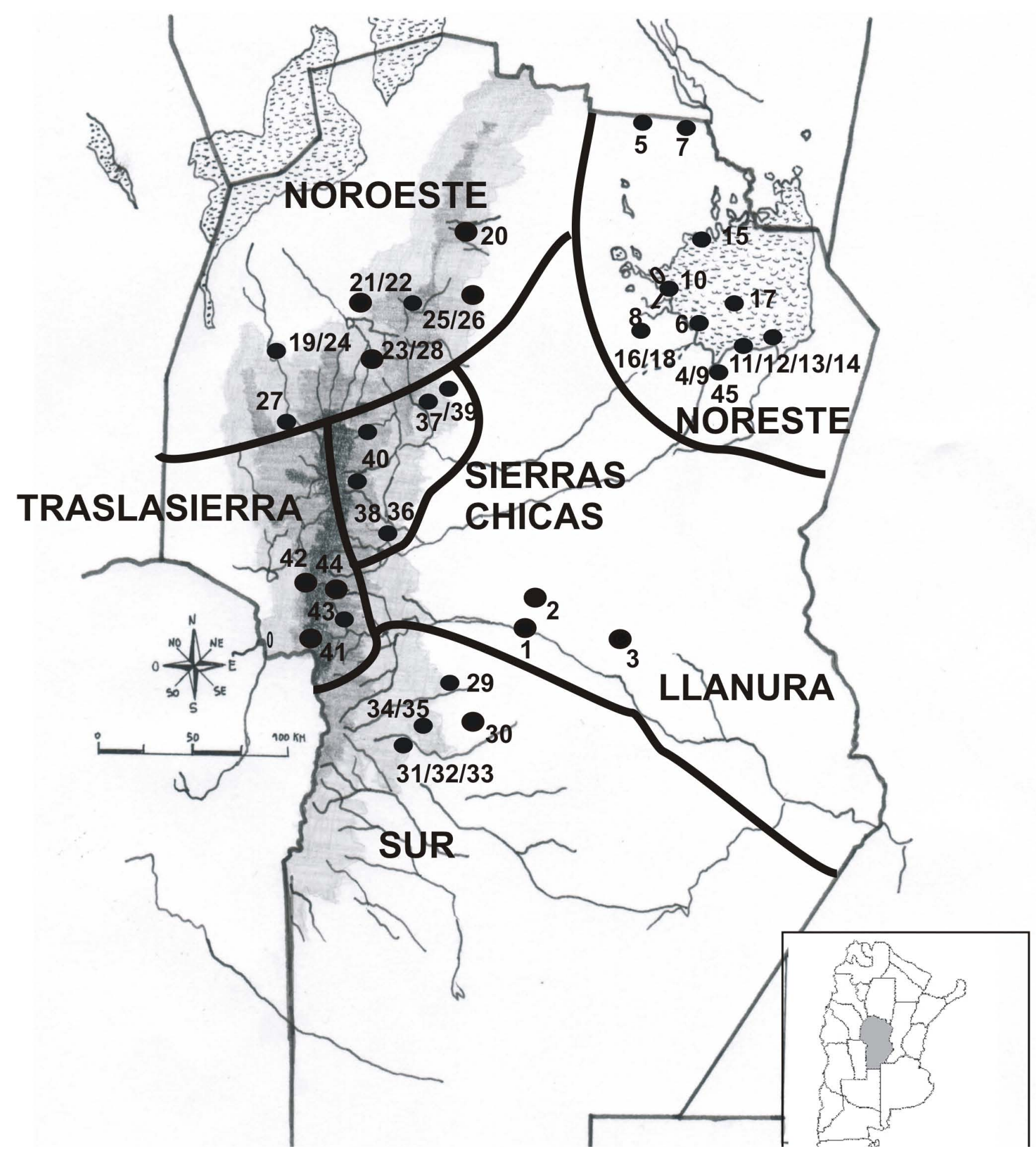

Figura 1. Mapa de la Provincia de Córdoba. Sitios arqueológicos considerados en este estudio, agrupados por subregiones geográficas: Llanura Extraserrana:1) Costasacate, 2) Cosme, 3) Rincón. Noreste:4) El Diquecito, 5) Laguna de la Sal, 6) Campo Mare, 7) Pozo de las Ollas, 8) Marull, 9) La Para, 10) Ea. La Elisa, 11) Orihuela, 12) Isla Orihuela, 13) Colonia Müller, 14) Miramar, 15) Isla Tigre, 16) El Silencio, 17) El Mistolar, 18) La Fortuna, 45) Laguna del Plata. Noroeste: 19) Rosca Yaco, 20) Cerro Colorado, 21) Nunsacat, 22) Ischilin, 23) San Esteban, 24) Charquina, 25) El Vado, 26) Río Seco 27), Guasapampa, 28) Corral de Piedra. Sur: 29) Yacanto, 30) Los Molinos y Potrero de Garay, 31) Quillinzo, 32) Va. Rumipal, 33) Banda Meridional del Lago, 34) Alto de las Conanas, 35) Paso Cabral. Sierras Chicas: 36) Parque Sarmiento, 37) La Granja, 38) Cuesta Blanca, 39) Cabana-Unquillo, 40)Ecoterra. Traslasierra: 41) Loma Bola, 42) Guasmara, 43) Va. de las Rosas, 44) Copina.

Figure 1. Sierras Pampeanas Southern region. Archaeological sites considered in this study grouped by geographic subregions. Plains:1) Costasacate, 2) Cosme, 3) Rincón. Northeast:4) El Diquecito, 5) Laguna de la Sal, 6) Campo Mare, 7) Pozo de las Ollas, 8) Marull, 9) La Para, 10) Ea. La Elisa, 11) Orihuela, 12) Isla Orihuela, 13) Colonia Müller, 14) Miramar, 15) Isla Tigre, 16) El Silencio, 17) El Mistolar, 18) La Fortuna, 45) Laguna del Plata. Northwest: 19) Rosca Yaco, 20) Cerro Colorado, 21) Nunsacat, 22) Ischilin, 23) San Esteban, 24) Charquina, 25) El Vado, 26) Río Seco 27), Guasapampa, 28) Corral de Piedra. South: 29) Yacanto, 30) Los Molinos y Potrero de Garay, 31) Quillinzo, 32) Va. Rumipal, 33) Banda Meridional del Lago, 34) Alto de las Conanas, 35) Paso Cabral. Sierras Chicas: 36) Parque Sarmiento, 37) La Granja, 38) Cuesta Blanca, 39) Cabana-Unquillo, 40)Ecoterra. Traslasierra: 41) Loma Bola, 42) Guasmara, 43) Va. de las Rosas, 44) Copina. 


\begin{tabular}{|c|c|c|c|c|}
\hline Región & Sitio Arqueológico & $\mathrm{F}$ & $\mathrm{M}$ & Museo \\
\hline Noreste & El Diquecito (4) & 3 & 3 & MHMLP \\
\hline Noreste & Campo Mare (6) & 3 & 1 & MHMLP \\
\hline Noreste & Estancia La Elisa (10) & 1 & - & MHMLP \\
\hline Noreste & Orihuela (11) & 1 & 2 & MAAM/MHMLP \\
\hline Noreste & Isla Orihuela (12) & - & 1 & MAAM \\
\hline Noreste & Pozo de las Ollas (7) & - & 1 & MA-UNC \\
\hline Noreste & Laguna de la Sal (5) & - & 1 & MA-UNC \\
\hline Noreste & Marull (8) & 1 & 1 & MA-UNC \\
\hline Noreste & La Para (9) & 1 & 2 & MHMLP \\
\hline Noreste & El Mistolar (17) & 1 & 1 & MHMLP \\
\hline Noreste & La Fortuna (18) & - & 1 & MHMLP \\
\hline Noreste & Miramar (14) & - & 1 & MAAM \\
\hline Noreste & Isla Tigre (15) & - & 1 & MA-UNC \\
\hline Noreste & Colonia Muller (13) & 1 & - & MAAM \\
\hline Noreste & El silencio/L.Surgentes (16) & 1 & 1 & MHMLP \\
\hline Noreste & Laguna del Plata (45) & - & 2 & MHMLP \\
\hline \multirow[t]{2}{*}{ Noreste } & Mar Chiquita & 1 & 1 & MHMLP \\
\hline & Total Noreste & 14 & 20 & \\
\hline Noroeste & Charquina (24) & - & 1 & MA-UNC \\
\hline Noroeste & Cerro Colorado (20) & 1 & 1 & MA-UNC \\
\hline Noroeste & San Esteban (23) & 1 & - & MA-UNC \\
\hline Noroeste & Ischilín (22) & - & 1 & MA-UNC \\
\hline Noroeste & Rosca Yaco (19) & - & 1 & MA-UNC \\
\hline Noroeste & Nunsacat (21) & 1 & 1 & MA-UNC \\
\hline Noroeste & El Vado (25) & 1 & - & MA-UNC \\
\hline Noroeste & Rio Seco-La Rinconada (26) & 1 & - & MHMLP \\
\hline Noroeste & Guasapampa (27) & 1 & - & MA-UNC \\
\hline \multirow[t]{2}{*}{ Noroeste } & Corral de Piedras (28) & - & 1 & MA-UNC \\
\hline & Total Noroeste & 5 & 7 & \\
\hline Llanura & Cosme (2) & 1 & - & MRII \\
\hline Llanura & Rincón (3) & 1 & 2 & MRII \\
\hline \multirow{2}{*}{ Llanura } & Costasacate (1) & 1 & - & MA-UNC \\
\hline & Total Llanura & 3 & 2 & \\
\hline Sierras Chicas & Cuesta Blanca (38) & - & 1 & MA-UNC \\
\hline Sierras Chicas & P. Sarmiento (36) & - & 2 & MA-UNC \\
\hline Sierras Chicas & La Granja (37) & 1 & - & MA-UNC \\
\hline Sierras Chicas & Cabana-Unquillo (39) & 1 & - & MA-UNC \\
\hline \multirow[t]{2}{*}{ Sierras Chicas } & Ecoterra (40) & - & 1 & MA-UNC \\
\hline & Total Sierras Chicas & 2 & 4 & \\
\hline Sur & Los Molinos (30) & 3 & 5 & MA-UNC \\
\hline Sur & Quillinzo (31) & - & 1 & MA-UNC \\
\hline Sur & Villa Rumipal (32) & - & 1 & MA-UNC \\
\hline Sur & Yacanto (29) & - & 1 & MA-UNC \\
\hline Sur & Potrero de Garay (30) & 1 & 1 & MA-UNC \\
\hline Sur & B. Meridional del Lago (33) & 1 & - & MEP \\
\hline Sur & Alto de las Conanas (34) & 1 & - & MHAPG \\
\hline \multirow[t]{2}{*}{ Sur } & Paso Cabral (35) & - & 1 & MA-UNC \\
\hline & Total Sur & 6 & 10 & \\
\hline Traslasierra & Guasmara (42) & - & 2 & MA-UNC \\
\hline Traslasierra & Copina (44) & - & 2 & MA-UNC \\
\hline Traslasierra & Villa de las Rosas (43) & 1 & - & MA-UNC \\
\hline \multirow[t]{3}{*}{ Traslasierra } & Loma Bola (41) & - & - & MA-UNC \\
\hline & Total Traslasierra & 2 & 5 & \\
\hline & Total & 33 & 47 & \\
\hline
\end{tabular}

Tabla 1. Procedencia geográfica de los 80 individuos de la región austral de las Sierras Pampeanas (Los números entre paréntesis indican la referencia en el mapa de la Figura 1). Referencias: Museo: MA-UNC-: Museo de Antropología, Facultad de Filosofía y Humanidades, Universidad Nacional de Córdoba -ciudad de Córdoba-, MHMLP: Museo Histórico Municipal La Para -ciudad de La Para-; MAAM: Museo de la región de Ansenuza "Aníbal Montes" -ciudad de Miramar-; MRII: Museo Arqueológico Provincial "Aníbal Montes" -ciudad de Río Segundo-; MEP: Museo Estrella de Piedra -Localidad de Villa Rumipal-; MHAPG: Museo Histórico Arqueológico -Localidad de Potrero de Garay-.

Table 1. Geographic provenience of the 80 individuals from the Sierras Pampeanas Southern region (numbers between parentheses corresponds to the reference in Figure 1). References: Museo: MA-UNC-: Museo de Antropología, Facultad de Filosofía y Humanidades, Universidad Nacional de Córdoba - Córdoba-, MHMLP: Museo Histórico Municipal La Para -La Para -; MAAM: Museo de la región de Ansenuza "Aníbal Montes" -Miramar-; MRII: Museo Arqueológico Provincial "Aníbal Montes" -Río Segundo-; MEP: Museo Estrella de Piedra -Villa Rumipal-; MHAPG: Museo Histórico Arqueológico -Potrero de Garay-. 
abscesos, pérdidas dentales ante mortem e hipoplasias de esmalte dental, entre otros- han demostrado ser una línea metodológica útil para discutir la importancia de los recursos en la dieta y salud, así como su variabilidad temporal y espacial (Larsen 1997; Lukacs 1989; Turner 1979), ya que ofrecen un registro independiente y complementario de otras evidencias arqueológicas (Walker et al. 1978).

La generación de esmalte dental es particularmente sensible de ser afectado por disturbios metabólicos originados por situaciones de estrés. La hipoplasia del esmalte dental (HDE) hace referencia a diversas perturbaciones fisiológicas en la producción de la matriz del esmalte por parte de los ameloblastos durante el proceso de crecimiento y desarrollo del diente, y afecta la morfología de la superficie de la corona (Barrientos 1999; Goodman y Armelagos 1988; Huss-Ashmore et al. 1982). Debe considerarse que el estrés capaz de provocar líneas de hipoplasias debe ser lo suficientemente severo o agudo como para requerir que el organismo deje de enviar energía de los procesos no vitales, y la traslade hacia los procesos que están siendo afectados. Es decir, que la detención del crecimiento de los huesos, dientes y otras estructuras puede considerarse como un proceso vital en la supervivencia de un organismo cuyas reservas nutricionales no son suficientes como para afrontar un evento estresor de esa magnitud. (Langsjoen 1998, Powell 1988).

Las principales causas de la formación de las hipoplasias del esmalte pueden ser hereditarias, traumas localizados o estrés metabólico a nivel sistémico (Goodman y Rose 1991; Hillson 1996). Entre las poblaciones arqueológicas, el estrés sistémico parece ser la principal causa de estos desórdenes (Goodman et al. 1980; Goodman y Rose 1991). Mientras la hipoplasia ha sido aceptada como un indicador general de disturbios sistémicos en el desarrollo (Hillson 1996), la sensibilidad y especificidad son todavía desconocidos (Goodman y Rose 1991).

En síntesis, la presencia de hipoplasia es considerada un indicador no específico del estrés fisiológico experimentado durante la niñez, en el momento de la formación de muchos de los tejidos óseos y dentales del cuerpo humano. Sin embargo, aún no está claro cuáles son los nutrientes críticos causantes de la condición, ni cómo interactúa la dieta con las enfermedades infecciosas para provocar deficiencias en la fisiología ameloblástica (Goodman y Rose 1991). De todos modos, existe un amplio consenso entre los investigadores de que las hipoplasias del esmalte dental pueden ser usadas para inferir la importancia de infecciones y/o deficiencias nutricionales durante la infancia y la niñez en una población (Goodman y Rose 1991; Langsjoen 1998; Lucaks 1989).

En este trabajo se analizaron también otras patologías, en este caso, de origen infeccioso según Lukacs (1989), tales como abscesos y pérdidas dentales ante mortem -PDAM-. Este autor aclara, en el caso de las PDAM, que si el origen se vincula con el desarrollo de abscesos o caries se las considera de origen infeccioso; por otra parte, si el origen etiológico se relaciona con el desgaste dental, se las considera dentro de las enfermedades degenerativas. Los abscesos son el resultado de una enfermedad pulpo-alveolar localizada, producto de la exposición y la contaminación bacteriana de la cavidad pulpar. Con la exposición de la cavidad pulpar se produce una respuesta inflamatoria ante las sustancias irritantes producidas por las bacterias (Hillson 1996) en donde los agentes infecciosos pueden destruir el hueso alveolar, que rodea la raíz del diente. Este proceso inflamatorio e infeccioso también puede extenderse más allá del hueso alveolar produciendo una o varias aperturas (cloacas) con la finalidad de expulsar el pus producto de la infección crónica. La destrucción de hueso alveolar destruye las estructuras de apoyo del diente, causando en muchos casos la pérdida de la pieza dental.

Las pérdidas dentales antemortem (PDAM) son aquellas producidas durante la vida del individuo, de gran valor diagnóstico, ya que dan cuenta de las distintas patologías a las cuales ha estado expuesto el individuo, así como a las presiones masticatorias ocurridas durante el consumo de alimentos, en función de sus características o por la realización de actividades relacionadas con la utilización de los dientes y la boca como herramienta. Las PDAM se pueden identificar como remodelaciones del tejido óseo periodontal o alveolar, el cual al dejar de actuar como sostén de la pieza dental comienza un proceso de reabsorción ósea (Buikstra y Ubelaker 1994; Lukacs 1989). Generalmente son varios los procesos que intervienen en la pérdida dental y la consecuente reabsorción de la tabla ósea, aunque muchas veces, su acción conjunta sea la que lo provoca (Hillson 2000). En las muestras óseas resulta muy difícil distinguir cuál de estos procesos ha sido el causante de la pérdida dental; generalmente se considera que una fuerte presión masticatoria, enfermedad periodontal, caries profundas y abscesos son los responsables, aunque pueden intervenir traumas, fracturas y otras causas difíciles de discernir sobre restos óseos (Scott y Turner 1988). Tomando en cuenta las diversas patologías predominantes en las arcadas dentales, así como el grado de desgaste dental, se intentará dar cuenta de las causas que provocaron PDAM en nuestra muestra, considerando las prevalencias reportadas por González (2011) para otras patologías, tales como caries, abscesos, elevados desgastes y periodontitis severa.

\section{Metodología}

Previo al registro de los bioindicadores dentales, se procedió al análisis bioantropológico de los restos, considerando los procedimientos establecidos por 
Buikstra y Ubelaker (1994) para la determinación del sexo y la estimación de edad en cada individuo. Para la estimación de la edad, se examinó cada caso y se lo incorporó a las categorías de adulto joven (20-35 años), adulto medio (35-50 años) y adulto mayor (> 50), siguiendo la propuesta de Buikstra y Ubelaker (1994) En aquellos casos en los que no se pudo establecer una categoría de edad especifica, se consideró al individuo como adulto.

En este estudio, las hipoplasias del esmalte fueron definidas como depresiones lineales y transversales del esmalte, tanto continuas como discontinuas (Barrientos 1999). El registro de las líneas se realizó por observación directa teniendo en cuenta su presencia/ausencia en todos los dientes, tanto del maxilar como de la mandíbula. La detección de las líneas se realizó de forma macroscópica, con una lupa de hasta 4 aumentos $(4 \mathrm{X})$ con iluminación oblicua. Con el fin de minimizar la probabilidad de incluir en el análisis de HDE aquellas que fueran producto de condiciones de estrés local, tales como el trauma, se siguieron las recomendaciones metodológicas de Barrientos (1999) y se excluyeron del análisis los casos en los que sólo se observó hipoplasias dentales en un solo diente.

En este trabajo se consideraron abscesos aquellos procesos osteolíticos concretos, denominados cloacas o fístulas. En cuanto a las PDAM, fueron incluidos tanto aquellos alvéolos en proceso de reabsorción como los totalmente reabsorbidos. Su registro se realizó de forma macroscópica, registrando presencia o ausencia y su ubicación en la arcada dental.

Se decidió evaluar la prevalencia de los distintos bioindicadores por individuo, y para el total de la muestra, considerando su distribución según sexo (femenino, masculino) y edad (adulto joven, adulto medio, adulto mayor, adulto). Asimismo, dado que uno de los objetivos del presente trabajo es indagar acerca de la diversidad temporal y espacial de la salud de los grupos humanos que vivieron en esta región en el Holoceno tardío, se consideró la cronología y la procedencia geográfica para proceder al agrupamiento de las muestras.

En cuanto a la cronología, se tuvo en cuenta la información radiocarbónica ${ }^{2}$ disponible sobre los individuos, así como los indicadores de cronología relativa -presencia de deformación artificial del cráneo e información arqueológica sobre los contextos de hallazgo-. Se subdividió la muestra en dos boques de una duración aproximada de mil años: Holoceno tardío inicial (25001500 años AP.) y Holoceno tardío final (1500-300 años

\footnotetext{
${ }^{2}$ Se dispone de 33 muestras fechadas por AMS sobre colágeno que las ubican en el Holoceno tardío, en un rango de $2707 \pm 61{ }^{14} \mathrm{C}$ años AP. y $383 \pm 5814 \mathrm{C}$ años AP., realizados en Graduate School of Frontier Sciences (University of Tokio) y Earth System Science Department (University of Irving).
}

AP.), los cuales se corresponderían con dos momentos en los cuales, según la evidencia arqueológica disponible, se habrían producido cambios en las estrategias de subsistencia y de forma más general, en los modos de vida de estas comunidades.

Como mencionamos anteriormente, el registro arqueológico de la región austral de las Sierras Pampeanas permite inferir, en momentos previos a la conquista española, ciertas diferencias regionales en cuanto al uso del espacio, el aprovechamiento de recursos, las prácticas mortuorias e incluso diferencias en cuanto a tecnologías tales como la cerámica (diferencias en cuanto a su manufactura y decoración) entre otros aspectos. Consideramos que estas diferencias que observamos en el registro arqueológico de los diversos sitios arqueológicos de este sector de las Sierras Pampeanas estarían reflejando diversas adaptaciones y procesos de diferenciación entre los grupos humanos, diferencias que también podrían reflejarse en cuanto a los alimentos consumidos, su procesamiento e incluso el aprovechamiento diferencial de los diversos recursos en función de su disponibilidad en los distintos ambientes de la región. Por ello, para indagar acerca de la diversidad espacial de la dieta, se tuvo en cuenta la proximidad geográfica entre los individuos, y se los agrupó considerando sub-regiones geográficoculturales: Sierras Chicas, Noreste, Noroeste, Llanura extraserrana, Sur y Traslasierra.

Finalmente, se efectuaron análisis estadísticos para determinar si las diferencias observadas en cuanto prevalencia eran significativas, mediante un test de Chicuadrado.

\section{Resultados}

\section{Bioindicadores de estrés metabólico}

En cuanto a las hipoplasias del esmalte dental (HDE), 33 individuos presentaron al menos una línea de hipoplasia del esmalte, representando el $41.25 \%$ del total relevado ${ }^{3}$. Se registraron 123 HDE sobre 1102 dientes, lo que establece una prevalencia de 11,16\% para la totalidad de la muestra.

En general, las hipoplasias del esmalte pueden formarse en todas las clases de dientes, aunque algunos estudios (Goodman et al. 1980) sugieren que la clase de diente con mayor sensibilidad para el registro de HDE es el canino inferior o mandibular, seguido en orden decreciente por el canino superior y los incisivos superiores e inferiores. En este trabajo de sometió la muestra dental a un análisis de sensibilidad (Isen) según la propuesta metodológica de Barrientos (1997, 1999) con la finalidad de comprobar si la distribución y formación de las HDE de la muestra concordaban con los datos aportados por los autores

\footnotetext{
3 Prevalencias calculadas a partir del número de individuos afectados/ total de individuos de la muestra.
} 


\begin{tabular}{|c|c|c|c|c|c|c|}
\hline & & $\begin{array}{c}\text { PDAM } \\
\text { Prevalencia }\end{array}$ & & $\begin{array}{c}\text { HDE } \\
\text { Prevalencia }\end{array}$ & & $\begin{array}{l}\text { ABSCESOS } \\
\text { Prevalencia }\end{array}$ \\
\hline Por edad & $\mathrm{P} / \mathrm{C}^{* *}$ & $(\%)$ & $P / C^{*}$ & $(\%)$ & $\mathrm{P} / \mathrm{C}^{* *}$ & $(\%)$ \\
\hline Adulto Joven & $20 / 349$ & $5.73 \%$ & $42 / 250$ & $16.80 \%$ & $10 / 349$ & $2.86 \%$ \\
\hline Adulto Medio & $54 / 509$ & $10.60 \%$ & $43 / 324$ & $13.27 \%$ & $44 / 509$ & $8.64 \%$ \\
\hline Adulto Mayor & $80 / 245$ & $32.65 \%$ & 4/99 & $4.04 \%$ & $36 / 245$ & $14.69 \%$ \\
\hline Adulto & $111 / 841$ & $13.19 \%$ & $34 / 429$ & $7.92 \%$ & $91 / 841$ & $10.82 \%$ \\
\hline \multicolumn{7}{|l|}{ Por sexo } \\
\hline Femenino & $170 / 834$ & $20.38 \%$ & $54 / 461$ & $11.71 \%$ & $68 / 834$ & $8.15 \%$ \\
\hline Masculino & $95 / 1110$ & $8.55 \%$ & $9 / 641$ & $10.76 \%$ & $113 / 1110$ & $10.18 \%$ \\
\hline \multicolumn{7}{|l|}{ Por Período } \\
\hline H. tardío inicial & $28 / 207$ & $13.52 \%$ & $6 / 116$ & $5.17 \%$ & $21 / 207$ & $9.85 \%$ \\
\hline H. tardío final & $61 / 802$ & $7.60 \%$ & $91 / 566$ & $16.07 \%$ & $52 / 802$ & $6.86 \%$ \\
\hline H. tardío & $176 / 920$ & $19.13 \%$ & $26 / 420$ & $6.19 \%$ & $108 / 920$ & $11.73 \%$ \\
\hline \multicolumn{7}{|l|}{ Por región } \\
\hline Noreste & $158 / 779$ & $20.28 \%$ & $26 / 373$ & $6.97 \%$ & 74/779 & $9.49 \%$ \\
\hline Noroeste & $48 / 263$ & $18.25 \%$ & 18/141 & $12.76 \%$ & $23 / 263$ & $8.74 \%$ \\
\hline Llanura & $7 / 143$ & $4.90 \%$ & $12 / 80$ & $15 \%$ & $12 / 143$ & $8.40 \%$ \\
\hline Sierras Chicas & $12 / 158$ & $7.60 \%$ & $7 / 77$ & $7.09 \%$ & $20 / 158$ & $12.65 \%$ \\
\hline Sur & $36 / 382$ & $9.42 \%$ & $28 / 248$ & $11.29 \%$ & $33 / 382$ & \multirow{2}{*}{$\begin{array}{l}8.36 \% \\
9.13 \%\end{array}$} \\
\hline Traslasierra & $4 / 219$ & $1.82 \%$ & $32 / 183$ & $17.48 \%$ & $20 / 219$ & \\
\hline TOTAL & 265/1944 & $13.63 \%$ & $123 / 1102$ & $11.16 \%$ & $181 / 1944$ & $9.31 \%$ \\
\hline
\end{tabular}

Tabla 2. Prevalencias totales. Referencias: $P / C^{*}$ : presencia de dientes afectados / Cantidad de piezas dentales observables. P/C**: presencia de alvéolos afectados / Cantidad de alvéolos observables.

Table 2. Total prevalences. References: P/C*: affected tooth presence/total observed teeth. P/C**: affected alveolus presence/total observed alveolus.

arriba citados. El análisis de la sensibilidad de cada una de las clases dentales a través del índice de sensibilidad (Isen) indicó que la clase con mayor sensibilidad para el registro de HDE es el canino inferior, seguido por el canino superior y el incisivo superior (datos no mostrados).

No se observaron diferencias notables entre sexos, presentando $11.71 \%$ y $10.76 \%$ de HDE los individuos femeninos y masculinos, respectivamente. En términos de los grupos de edad analizados, se observa una relación entre la edad de los individuos y la presencia de HDE: así, los adultos jóvenes (16.80\%) y medios (13.27\%) serían quienes más han evidenciado signos de esta patología. Regionalmente, las mayores prevalencias de HDE se presentan en Traslasierra (17.48\%), Llanura (15\%) y Noroeste (12.76\%). En cuanto a la distribución temporal de las HDE, se observa una diferencia notable entre el Holoceno tardío inicial (6.19\%) y el Holoceno tardío final

\section{(16.07\%) (Tabla 2).}

Por otra parte cuando combinamos la información de las distintas variables consideradas, en este caso la prevalencia de HDE en distintos momentos del Holoceno y su prevalencia según el sexo, se observa que en el Holoceno tardío inicial los individuos de sexo masculino $(7.40 \%)$ son los que presentan los mayores valores, mientras que en momentos finales son los individuos de sexo femenino (17.46\%) quienes presentan las mayores prevalencias de esta patología (Tabla 3).

Por otra parte, cuando evaluamos la prevalencia de HDE según las categorías de edad y su distribución cronológica, observamos que los individuos adultos jóvenes y mayores no presentan evidencia de esta patología; en cambio, debe destacarse un aumento de las frecuencias en todas las categorías de edad hacia fines del Holoceno tardío,

\begin{tabular}{|c|c|c|c|c|c|c|c|c|c|}
\hline \multirow[b]{2}{*}{ Sexo } & \multirow[b]{2}{*}{ Nro. Ind. } & \multicolumn{2}{|c|}{ HTI } & \multicolumn{3}{|c|}{ HTF } & \multicolumn{3}{|c|}{ HTF } \\
\hline & & $P / C$ & $(\%)$ & Nro. Ind. & $\mathrm{P} / \mathrm{C}$ & $(\%)$ & Nro. Ind. & $P / C$ & (\%) \\
\hline \multirow{2}{*}{$\begin{array}{c}\mathrm{F} \\
\mathrm{M}\end{array}$} & 5 & $4 / 89$ & 4.49 & 11 & $33 / 189$ & 17.46 & 18 & $17 / 183$ & 9.28 \\
\hline & 4 & $2 / 27$ & 7.4 & 21 & $58 / 377$ & 15.38 & 21 & 9/237 & 3.79 \\
\hline Total & 9 & $6 / 116$ & 5.17 & 32 & $91 / 566$ & 16.07 & 39 & $26 / 420$ & 6.19 \\
\hline
\end{tabular}

Tabla 3. Cantidad de individuos con hipoplasia del esmalte dental y prevalencia, considerando sexo y por período cronológico. Referencias: P/C: presencia de piezas dentales afectados / Cantidad de piezas dentales observables; N Ind.: Número de individuos; \%: prevalencia; F: femenino; M: masculino; HTI: Holoceno tardío inicial; HTF: Holoceno tardío final; HT: Holoceno tardío.

Table 3. Number of individuals with dental hypoplasia and prevalences, considering sex and chronological period. References: P/C: affected tooth presence/total observed teeth. $N^{\circ}$ Ind: number of individuals; \%: prevalence; F: female; M: male; HTI: initial late Holocene, HTF: later late Holocene; HT: late Holocene 


\begin{tabular}{|c|c|c|c|c|c|c|c|c|c|}
\hline \multirow[b]{2}{*}{ Edad } & \multirow[b]{2}{*}{ Nro. Ind. } & \multicolumn{2}{|c|}{ HTI } & \multicolumn{3}{|c|}{ HTF } & \multicolumn{3}{|c|}{ HTF } \\
\hline & & $\mathrm{P} / \mathrm{C}$ & (\%) & Nro. Ind. & $\mathrm{P} / \mathrm{C}$ & (\%) & Nro. Ind. & $\mathrm{P} / \mathrm{C}$ & (\%) \\
\hline AJ & 0 & $0 / 0$ & 0 & 6 & $28 / 122$ & 22.95 & 8 & $14 / 128$ & 10.93 \\
\hline AMD & 3 & $4 / 70$ & 6.00 & 10 & $37 / 200$ & 18.5 & 5 & $2 / 54$ & 3.70 \\
\hline AM & 1 & $0 / 16$ & 0 & 1 & $1 / 6$ & 16.66 & 7 & $3 / 77$ & 3.89 \\
\hline$A$ & 5 & $2 / 30$ & 6.66 & 15 & $25 / 238$ & 10.54 & 19 & $7 / 161$ & 4.34 \\
\hline Total & 9 & $6 / 116$ & 5.17 & 32 & $91 / 566$ & 16.07 & 39 & $26 / 420$ & 6.19 \\
\hline
\end{tabular}

Tabla 4. Cantidad de individuos y prevalencia de HDE en función de los grupos de edad y por período cronológico. Referencias: P/C: presencia de piezas dentales afectados / Cantidad de piezas dentales observables; $N^{\circ}$ Ind.: Número de individuos; \%: prevalencia.; AJ: Adulto joven; AMD: Adulto medio; AM: Adulto mayor; A: Adulto; HTI: Holoceno tardío inicial; HTF: Holoceno tardío final; HT: Holoceno tardío.

Table 4. Number of individuals with dental hypoplasia and prevalences, considering age and chronological period. References: P/C: affected tooth presence/total observed teeth. $N^{\circ}$ Ind: number of individuals; \%: prevalence; AJ: young adult; AMD: middle adult; AM: old adult; HTI: initial late Holocene, HTF: later late Holocene; HT: late Holocene

principalmente en adultos jóvenes (22.95\%) y medios $(18.5 \%)$ (Tabla 4).

\section{Bioindicadores de origen infeccioso/degenerativo}

En cuanto a abscesos, del total de individuos relevados 53 presentaban esta patología, lo cual representa el $66.25 \%$. Se registraron 181 abscesos sobre un total de 1944 alvéolos -9.31\%- (Tabla 2).

Teniendo en cuenta las prevalencias para el total de la muestra, se observa que esta patología se presenta con mayor frecuencia en individuos masculinos (10.18\%). En términos de los grupos de edad analizados, se observa una covariación positiva entre la edad y la presencia de abscesos, incrementándose notoriamente con el avance de la edad: así, los individuos adultos mayores (14.69\%) y adultos medios (8.64\%) presentan las prevalencias más altas del total de la muestra. Al analizar la distribución regional de esta patología, observamos que en la región de Sierras Chicas (12.65\%) son más frecuentes las infecciones alveolares. Finalmente, al evaluar la prevalencia de esta patología en distintos momentos del Holoceno tardío, los resultados indican que esta patología tiene mayor frecuencia en momentos iniciales del Holoceno tardío (9.85\%) (Tabla 2).

Por otra parte, cuando evaluamos la prevalencia de los abscesos en distintos momentos del Holoceno considerando el sexo de los individuos, observamos que los masculinos presentan mayores valores en el Holoceno tardío inicial (13.40\%) y en el Holoceno tardío
(13.45\%) (Tabla 5). Asimismo, los adultos mayores tienen valores elevados en todos los períodos, elevándose hacia momentos finales del Holoceno (Tabla 6)

Por otra parte, las PDAM se registraron en 47 individuos, representando el $58.75 \%$ del total de individuos relevados. Se relevaron 265 PDAM sobre un total de 1944 alvéolos (13.63\%). Al considerar la prevalencia de PDAM en el total de la muestra, según el sexo de los individuos, los femeninos (20.38\%) presentan frecuencias mucho más elevadas de PDAM que los masculinos (8.55\%). Al igual que lo observado en abscesos, las PDAM se incrementan notoriamente en los individuos de edad avanzada. Los resultados revelan que esta patología tiene mayor incidencia en las regiones Noreste (20.28\%) y Noroeste (18.25\%), siendo notoriamente baja su presencia en la región de Traslasierra (1.82\%). Para el total de la muestra, la mayor incidencia de esta patología se habría dado en el Holoceno tardío inicial (13.52\%) (Tabla 2).

Cuando se evaluó las prevalencias de esta patología considerando el sexo de los individuos y su cronología, se observó que en momentos iniciales del Holoceno tardío los valores son similares tanto para individuos femeninos (12.40\%) como masculinos (11.53\%), mientras que en momentos finales las prevalencias en femeninos (11.86\%) se mantienen, y en los masculinos (3.37\%) disminuyen (Tabla 7). Por último, cuando consideramos su distribución etaria, observamos que la pérdida de piezas dentales se incrementa con el avance de la edad: así vemos que en todos los períodos los individuos adultos mayores son quienes presentan los valores más elevados,

\begin{tabular}{cccccccccc}
\hline & \multicolumn{1}{c}{ HTI } & \multicolumn{1}{c}{ HTF } & \multicolumn{3}{c}{ HTF } & \multicolumn{2}{c}{ P/C } & $(\%)$ \\
\hline Sexo & Nro. Ind. & P/C & $(\%)$ & Nro. Ind. & P/C & (\%) & Nro. Ind. & P.79 \\
F & 5 & $8 / 129$ & 6.20 & 11 & $19 / 239$ & 7.94 & 18 & $41 / 466$ \\
Total & 4 & $13 / 78$ & 13.54 & 21 & $33 / 563$ & 6.87 & 21 & $67 / 469$ & 13.45 \\
\hline
\end{tabular}

Tabla 5. Cantidad de individuos con abscesos y prevalencia, considerando sexo y por periodo cronológico. Referencias: P/C: presencia de alvéolos afectados / Cantidad de alvéolos observables; Nº Ind. Número de individuos; \%: prevalencia; F: femenino; M: masculino; HTI: Holoceno tardío inicial; HTF: Holoceno tardío final; HT: Holoceno tardío.

Table 5. Number of individuals with abscesses and prevalences, considering sex and chronological period. References: P/C: affected alveolus presence/total observed alveolus. No Ind: number of individuals; \%: prevalence; F: female; M: male; HTI: initial late Holocene, HTF: later late Holocene; HT: late Holocene. 


\begin{tabular}{|c|c|c|c|c|c|c|c|c|c|}
\hline \multirow[b]{2}{*}{ Edad } & \multirow[b]{2}{*}{ Nro. Ind. } & \multicolumn{2}{|c|}{ HTI } & \multicolumn{3}{|c|}{ HTF } & \multicolumn{3}{|c|}{ HTF } \\
\hline & & $\mathrm{P} / \mathrm{C}$ & (\%) & Nro. Ind. & $\mathrm{P} / \mathrm{C}$ & $(\%)$ & Nro. Ind. & $\mathrm{P} / \mathrm{C}$ & $(\%)$ \\
\hline AJ & 0 & $0 / 0$ & 0 & 6 & $2 / 158$ & 7.94 & 8 & $8 / 191$ & 4.18 \\
\hline AMD & 3 & $5 / 96$ & 5.20 & 10 & $14 / 285$ & 4.91 & 5 & $25 / 128$ & 19.53 \\
\hline AM & 1 & $3 / 25$ & 12.00 & 1 & $4 / 15$ & 26.70 & 7 & $29 / 205$ & 14.14 \\
\hline$A$ & 5 & $13 / 86$ & 15.11 & 15 & $32 / 359$ & 8.91 & 19 & $46 / 396$ & 11.61 \\
\hline Total & 9 & $21 / 207$ & 10.14 & 32 & $52 / 817$ & 6.36 & 39 & $108 / 920$ & 11.73 \\
\hline
\end{tabular}

Tabla 6. Cantidad de individuos y prevalencia de abscesos en función de los grupos de edad y por período cronológico. Referencias: P/C: presencia de alvéolos afectados / Cantidad de alvéolos observables; N Ind. Número de individuos; \%: prevalencia.; AJ: Adulto joven; AMD: Adulto medio; AM: Adulto mayor; A: Adulto; HTI: Holoceno tardío inicial; HTF: Holoceno tardío final; HT: Holoceno tardío.

Table 6. Number of individuals with abscesses and prevalences, considering age and chronological period. References: P/C: affected alveolus presence/total observed alveolus. No Ind: number of individuals; \%: prevalence; AJ: young adult; AMD: middle adult; AM: old adult; A: adult; HTI: initial late Holocene, HTF: later late Holocene; HT: late Holocene.

particularmente en momentos iniciales del Holoceno tardío (48\%) (Tabla 8).

Luego de calcular las prevalencias para cada uno de los indicadores de salud bucal en función de variables tales como el sexo y edad de los individuos, las regiones geográfico-culturales de procedencia de las muestras, la cronología, y las distintas combinaciones posibles, se efectúo un test de Chi-cuadrado, el cual permite testear la correlación entre la frecuencia de los distintos indicadores y las variables mencionadas, y determinar si las diferencias observadas son significativas.

En primer lugar, considerando los datos pertenecientes a la totalidad de la muestra, se observan diferencias estadísticamente significativas en la frecuencia de hipoplasia del esmalte dental, siendo ésta más frecuente en el Holoceno tardío final (Tabla 9, sólo se presentan los resultados significativos).

Luego, se evaluaron las prevalencias en función de la procedencia geográfica de las muestras: se observa que en las regiones de Noreste y Traslasierra es más frecuente la presencia de hipoplasia del esmalte dental y en Sierras Chicas son más frecuentes las pérdidas dentales ante mortem. Asimismo, en las tres regiones estos indicadores de salud bucal son más frecuentes en el Holoceno tardío final; así también en la región de Traslasierra es más frecuente la presencia de pérdidas dentales antemortem en el mismo período cronológico.

En la región de Traslasierra, al realizar las comparaciones por sexo y edad, se observó que la presencia de hipoplasia del esmalte era estadísticamente significativa en individuos de sexo masculino, así como la presencia de abscesos en individuos adultos y adultos medios.

Continuando con la idea de realizar diversas comparaciones entre las variables, se decidió agrupar las muestras a nivel de grandes regiones geográfico-culturales: así, se agruparon por un lado las regiones ubicadas al Este del actual territorio provincial, y por otro, las regiones ubicadas el Oeste, pertenecientes a la región serrana: se las denominó Noreste-Llanura y Noroeste-Traslasierra. Al someter estas agrupaciones al test de Chi-Cuadrado se observaron diferencias estadísticamente significativas en la presencia de hipoplasia del esmalte dental en las regiones Noreste-Llanura en el Holoceno tardío final.

\section{Discusión}

Si retomamos la hipótesis de trabajo planteada en la Introducción, proponíamos que entre los siglos XII y XV de la era cristiana las poblaciones que habitaron esta región se habrían visto sometidas a una serie de cambios o presiones -de tipo ambiental, demográfico y/o sociallos cuales habrían impactado negativamente en el modo y las condiciones de vida de las sociedades indígenas, generando un desmejoramiento de las condiciones generales de salud, en comparación con momentos previos. Se esperaba encontrar en el registro dental un incremento de los indicadores de estrés metabólico (hipoplasia del esmalte dental) y mayor incidencia de enfermedades pulpo-alveolares (pérdidas dentales ante

\begin{tabular}{cccccccccc}
\hline & & \multicolumn{2}{c}{ HTI } & \multicolumn{3}{c}{ HTF } & \multicolumn{3}{c}{ HTF } \\
Sexo & Nro. Ind. & P/C & $(\%)$ & Nro. Ind. & P/C & (\%) & Nro. Ind. & P/C \\
\hline F & 5 & $16 / 129$ & 12.40 & 11 & $42 / 254$ & 11.86 & 18 & $112 / 451$ & 24.83 \\
M & 4 & $9 / 78$ & 11.53 & 21 & $19 / 563$ & 3.37 & 21 & $67 / 469$ & 14.28 \\
Total & $\mathbf{9}$ & $\mathbf{2 5 / 2 0 7}$ & $\mathbf{1 2 . 0 7}$ & $\mathbf{3 2}$ & $\mathbf{6 1 / 8 1 7}$ & $\mathbf{7 . 4 6}$ & $\mathbf{3 9}$ & $\mathbf{1 7 9 / 9 2 0}$ & $\mathbf{1 9 . 4 5}$ \\
\hline
\end{tabular}

Tabla 7. Cantidad de individuos con PDAM, y prevalencia de esta patología, considerando el sexo y el periodo cronológico de su ocurrencia. Referencias: P/C: presencia de alvéolos afectados / Cantidad de alvéolos observables; $N^{\circ}$ Ind. Número de individuos; \%: prevalencia; F: femenino; M: masculino; HTI: Holoceno tardío inicial; HTF: Holoceno tardío final; HT: Holoceno tardío.

Table 7. Number of individuals with premortem tooth loss and prevalences, considering sex and chronological period. References: P/C: affected alveolus presenceltotal observed alveolus. $N^{\circ}$ Ind: number of individuals; \%: prevalence; F: female; M: male; HTI: initial late Holocene, HTF: Iater late Holocene; HT: late Holocene. 


\begin{tabular}{|c|c|c|c|c|c|c|c|c|c|}
\hline \multirow[b]{2}{*}{ Edad } & \multicolumn{3}{|c|}{ HTI } & \multicolumn{3}{|c|}{ HTF } & \multicolumn{3}{|c|}{ HTF } \\
\hline & Nro. Ind. & $P / C$ & (\%) & Nro. Ind. & $P / C$ & (\%) & Nro. Ind. & P/C & (\%) \\
\hline AJ & 0 & $0 / 0$ & 0 & 6 & 7/158 & 4.33 & 8 & 13/191 & 6.88 \\
\hline AMD & 3 & $3 / 96$ & 3.13 & 10 & $32 / 285$ & 11.2 & 5 & $19 / 128$ & 14.84 \\
\hline AM & 1 & $12 / 25$ & 48.00 & 1 & $3 / 15$ & 20.00 & 7 & $65 / 205$ & 31.07 \\
\hline A & 5 & $10 / 86$ & 11.62 & 15 & $19 / 359$ & 5.29 & 19 & $82 / 396$ & 20.70 \\
\hline Total & 9 & $28 / 207$ & 13.52 & 32 & $61 / 817$ & 7.46 & 39 & $179 / 920$ & 19.45 \\
\hline
\end{tabular}

Tabla 8. Cantidad de individuos y prevalencia de PDAM en función de los grupos de edad y por período cronológico. Referencias: P/C: presencia de alvéolos afectados / Cantidad de alvéolos observables; № Ind. Número de individuos; \%: prevalencia.; AJ: Adulto joven; AMD: Adulto medio; AM: Adulto mayor; A: Adulto; HTI: Holoceno tardío inicial; HTF: Holoceno tardío final; HT: Holoceno tardío.

Table 8. Number of individuals with premortem tooth loss and prevalences, considering age and chronological period. References: P/C: affected alveolus presence/total observed alveolus. No Ind: number of individuals; \%: prevalence; AJ: young adult; AMD: middle adult; AM: old adult; A: adult; HTI: initial late Holocene, HTF: later late Holocene; HT: late Holocene.

mortem, abscesos) en momentos previos a la conquista española.

En nuestra región, en el caso de la hipoplasia del esmalte dental se observó que hacia momentos iniciales del Holoceno tardío los individuos masculinos presentan mayor prevalencia; en cambio, hacia momentos finales se produce un aumento notable de este indicador, siendo los individuos femeninos quienes presentan mayores prevalencias. Por otro lado, en el Holoceno tardío inicial los individuos adultos jóvenes y mayores no presentan hipoplasias; en cambio, debe destacarse que hacia momentos finales del Holoceno se evidencia un aumento de las frecuencias en todas las categorías de edad, principalmente en adultos jóvenes y medios. Se observaron diferencias estadísticamente significativas en momentos finales del Holoceno para individuos masculinos, adultos jóvenes y medios de las regiones de

\begin{tabular}{|c|c|c|c|c|c|c|c|c|c|c|c|c|}
\hline & \multicolumn{4}{|c|}{ HDE } & \multicolumn{4}{|c|}{ ABSC. } & \multicolumn{4}{|c|}{ PDAM } \\
\hline & $A / P^{*}$ & $x^{2}$ & Prob. & gl. & $A / P^{*}$ & $x^{2}$ & Prob. & gl. & $A / P^{*}$ & $x^{2}$ & Prob. & gl. \\
\hline \multicolumn{13}{|c|}{$\begin{array}{l}\text { Considerando el total de la } \\
\text { muestra } \\
\text { Por cronología }\end{array}$} \\
\hline H. tardío inicial & $8 / 2$ & - & - & - & - & - & - & - & - & - & - & - \\
\hline H. tardío final & $10 / 20$ & - & - & - & - & - & - & - & - & - & - & - \\
\hline H. tardío & $29 / 11$ & - & - & - & - & - & - & - & - & - & - & - \\
\hline Total & $47 / 33$ & 12.981 & 0.002 & 2 & - & - & - & - & - & - & - & - \\
\hline
\end{tabular}

\section{Considerando la región}

Noreste

Por cronología

H. tardío inicial

H. tardío final

H. tardío

Total

Traslasierra

Por cronología

$$
\text { H. tardío final }
$$

H. tardío

Total

Por sexo

Femenino

Masculino

Total

Por edad

Adulto Joven

Adulto Medio

Adulto

Total

\begin{tabular}{|c|c|c|c|c|c|c|c|c|c|c|c|}
\hline $3 / 0$ & - & - & - & - & - & - & - & - & - & - & - \\
\hline $2 / 5$ & - & - & - & - & - & - & - & - & - & - & - \\
\hline $20 / 4$ & - & - & - & - & - & - & - & - & - & - & - \\
\hline $25 / 9$ & 9.534 & 0.009 & 2 & - & - & - & - & - & - & - & - \\
\hline
\end{tabular}

Sierras Chicas

Por cronología
H. tardío inicia
H. tardío final
H. tardío

Total

\begin{tabular}{|c|c|c|c|c|c|c|c|c|c|c|c|}
\hline $10 / 5$ & - & - & - & - & - & - & - & - & - & - & - \\
\hline $2 / 1$ & - & - & - & - & - & - & - & - & - & - & - \\
\hline $2 / 6$ & 4.444 & 0.035 & 1 & - & - & - & - & - & - & - & - \\
\hline $2 / 1$ & - & - & - & - & - & - & - & - & - & - & - \\
\hline $0 / 5$ & - & - & - & - & - & - & - & - & - & - & - \\
\hline $2 / 6$ & 4.444 & 0.035 & 1 & - & - & - & - & - & - & - & - \\
\hline - & - & - & - & $2 / 0$ & - & - & - & - & - & - & - \\
\hline- & - & - & - & $0 / 3$ & - & - & - & - & - & - & - \\
\hline- & - & - & - & $0 / 3$ & - & - & - & - & - & - & - \\
\hline- & - & - & - & $2 / 6$ & 8 & 0.018 & 2 & - & - & - & - \\
\hline
\end{tabular}

Tabla 9. Resultados estadísticamente significativos. Test Chi-Cuadrado. Referencias: * número de individuos que no han sido afectados/ número de individuos afectados; ** número total de afecciones/número total de alvéolos.

Table 9. Statistically significant results. Chi-square test. References:* number of individuals unaffected/ number of individuals affected; ** total number of affections/total number of alveolus. 


\section{Traslasierra y Noreste.}

Por otra parte, para pérdidas dentales ante mortem y abscesos se observa un patrón contrario al esperado, ya que ambos son más frecuentes en el Holoceno tardío inicial. En el caso de las pérdidas dentales, en momentos iniciales los valores son similares tanto para individuos femeninos como masculinos, mientras que en momentos finales del Holoceno tardío las prevalencias en femeninos se mantienen, y en los masculinos disminuyen: esta continuidad en los valores para femeninos podría estar relacionada con el aumento de las infecciones cariosas hacia momentos finales del Holoceno tardío (Fabra y González 2008, 2011; González 2011), ya que generalmente las pérdidas dentales ante mortem se asocian a la extensión de este tipo de patologías hacia la raíz de las piezas dentales, produciéndose en muchos casos la pérdida del diente (Lukacs 1995). Por otro lado, los abscesos son más frecuentes en el Holoceno tardío inicial en individuos masculinos, y en la región de Traslasierra. De forma similar a lo observado en todas las patologías infecciosas registradas en este trabajo, los abscesos también se incrementan con el avance de la edad.

Contrariamente a las expectativas bioarqueológicas planteadas para esta hipótesis, observamos que los individuos que habitaron en los momentos iniciales del Holoceno tardío presentaron mayores frecuencias de abscesos y PDAM que en el Holoceno tardío final. Como mencionamos anteriormente, estas patologías están asociadas a diversos factores, entre ellos un desgaste dental severo, la formación de caries profundas, un trauma o fractura coronaria o incluso enfermedad periodontal severa (Park 1991; Ortner 2003) Sin embargo, en los casos analizados en el presente trabajo, suponemos que estas patologías pueden estar vinculadas tanto a la presencia de caries como a grados elevados de desgaste dental: de manera preliminar, se relevó en esta muestra esta patología, y para momento iniciales, el $60 \%$ de la dentición presentaría desgaste dental grave (González, en preparación), desgaste que implica exposición de dentina llegando a funcionar la raíz como superficie oclusal, es decir, que ha llegado a afectar la funcionalidad de la pieza dental, pudiendo provocar infecciones varias que derivaran en abscesos o en la pérdida de la pieza dentaria.

Sin embargo, debe tenerse en cuenta esta continuidad en las prevalencias de las pérdidas dentales ante mortem entre los individuos femeninos desde el Holoceno tardío inicial al final: este patrón no estaría indicando puntualmente un desmejoramiento de la salud entre los siglos XII y XV de la era cristiana, pero sí nos podría estar informando sobre la continuidad de algunas prácticas, entre ellas las alimenticias.

En el caso de las hipoplasias del esmalte, algunos autores concluyen que los factores relacionados con situaciones de deterioro nutricional son la principal causa de la aparición de hipoplasias (Buikstra y Ubelaker 1994). Los factores potenciales que pueden producir hipoplasias de esmalte son múltiples: entre ellos deben mencionarse perturbaciones derivadas de problemas genéticos, traumas localizados, enfermedades gastrointestinales, baja exposición a la luz solar, procesos infecciosos, déficit proteico, entre otros (Hillson 1986, 1996; Lukacs 1989; Ortner 2003).

Consideramos que la presencia de hipoplasias del esmalte en las poblaciones analizadas puede relacionarse con episodios de estrés, los cuales podrían estar posiblemente vinculados a: a) cambios en la alimentación -la posible incorporación de alimentos cultivados tales como el maíz a la dieta habría generado un cambio alimenticio que en primera instancia derivaría en un deterioro nutricional (Cohen y Armelagos 1984; Larsen 1997) y/o b) reducción en la disponibilidad de recursos a causa de la posible presión demográfica y ambiental producida a fines del Holoceno tardío (Laguens 1999).

Con relación al primer punto, respecto a la incidencia que tendría el advenimiento de la producción de alimentos en los distintos grupos humanos, en general ha sido asociado con un desmejoramiento de la salud de las sociedades agrícolas tempranas, en comparación con la situación previa observada en cazadores-recolectores, donde el estado general de salud de estas poblaciones es interpretado principalmente como derivado de un ingesta centrada en el consumo de carne y otros alimentos animales. En aquellos casos en los que se ha registrado la presencia de hipoplasia del esmalte en cazadoresrecolectores, esta patología ha sido relacionada con el aumento demográfico, conflictos inter e intragrupales, nucleamiento y/o aislamiento poblacional (Barrientos 1999; Cohen y Armelagos 1984; García Guraieb 2004, 2006; Keenleyside 1998; Larsen 1987; Starling 2007). En poblaciones con agricultura incipiente (Larsen 1997; Starling 2007) esta patología se ha relacionado con el estrés producido por el cambio en los hábitos alimenticios: el desmejoramiento se traduciría en grandes eventos de estrés, relacionados a la reducción en la diversidad de alimentos y la dependencia casi exclusiva a un alimento. Altos grados de prevalencia de hipoplasias son sistemáticamente identificados en poblaciones que basan su subsistencia en la agricultura (Hillson 1996; Larsen 1995; Smith 1984). Los altos niveles de ingesta de maíz son vistos como una de las causas fundamentales que producen una tendencia a aumentar la cantidad de hipoplasias por individuo; en general, el alto contenido de fitatos que posee el maíz puede inhibir la absorción de minerales, entre ellos el hierro. Su ausencia en la dieta se asocia con anemias y desnutrición. (Cohen y Armelagos 1984; Huss - Ashmore et al. 1982; Larsen 1995).

En la región austral de las Sierras Pampeanas las evidencias de la producción y consumo de cultivos como maíz no 
son concluyentes ${ }^{4}$, y la evidencia arqueológica sugiere que la base económica de estas poblaciones era de tipo mixta, es decir que el consumo de alimentos agrícolas habría cubierto al menos el $50 \%$ de la subsistencia, con el resto dividido en un 30\% para la recolección, y el 20\% restante para la caza (Laguens 1999; Laguens et al. 2007). Según la información isotópica que se posee para esta región (Laguens et al. 2009), la agricultura posiblemente del maíz se habría incorporado de forma parcial a la dieta de estas poblaciones, a finales del Holoceno tardío y su incidencia no habría sido un fenómeno coetáneo en todas las regiones. Laguens y colaboradores (2009) sugieren que la agricultura en las regiones de Sierras Chicas y Traslasierra se habría incorporado en momentos previos a la conquista española, muy posteriormente a lo que habría ocurrido en otras regiones, como Noreste o Llanura, siempre de forma complementaria a una estrategia económica mixta, debido a que los valores obtenidos de ${ }^{13} \mathrm{C}$ en las regiones de Sierras Chicas y Traslasierra rondan entre $-16 \%$ o y $-17.7 \%$, sugiriendo una dieta basada principalmente en alimentos de tipo $C_{3}$ en cambio para las regiones de Noreste y Llanura los valores de ${ }^{13} \mathrm{C}$ presentan valores más positivos, entre $-11.8 \% \mathrm{y}$ $-15.3 \%$. Entonces podríamos decir que la frecuencia de hipoplasia registrada, especialmente en Traslasierra, no se relaciona necesariamente al mayor consumo de maíz, ya que los resultados de isótopos estables indicaron que hacia momentos finales del Holoceno tardío, el consumo de maíz en esta región no habría sido preponderante en la dieta de estas poblaciones. En cambio, en la región Noreste donde también se registró mayor presencia de hipoplasias, los valores isotópicos sugerirían una mayor importancia de este cereal en la dieta. Sin embargo, en esta región todavía las evidencias arqueológicas son escasas en relación a los modos de vida y alimentación, principalmente la evidencia sobre cultígenos (Bonofiglio 2004, 2009). Consideramos fundamental ampliar y profundizar los estudios isotópicos, no sólo sobre muestras humanas sino sobre los recursos potencialmente consumidos en estas regiones, para acercarnos de forma más precisa al estudio de las pautas alimenticias y sus implicancias en la salud de estas poblaciones.

Con relación al segundo punto, en cuanto a la posibilidad de una reducción en la disponibilidad de los recursos alimenticios, consideramos que existen elementos para pensar que este factor, junto a cambios en la dieta, podría haber originado los episodios de estrés evidenciados a través de la presencia de hipoplasias del esmalte.

\footnotetext{
${ }^{4}$ En general, la referencia sobre prácticas agrícolas surge de las fuentes etnohistóricas, donde se relata la presencia de maizales y chacras cerca de las casas o dispersas en distintos lugares de las sierras, lejos de los lugares de asentamiento. La evidencia más directa de prácticas de cultivo ha sido aportada por la arqueobotánica: Pastor (2006), Medina y Pastor (2006), López (2007) y Medina et al. (2009) han detectado la presencia de macrorestos vegetales de Phaseolus sp., y fitolitos pertenecientes a Zea mays y Cucúrbita sp., asociados a una posible estructura de cultivo y a paredes de restos cerámicos fechados entre el $716 \pm 39$ y $854 \pm 39$ años A.P. (Medina et al. 2009).
}

Las prácticas económicas sobre el ambiente definen territorios de explotación, los cuales según la estrategia de expropiación (caza, recolección, agricultura) alcanzan un tamaño concreto: aquellas estrategias que exijan mayores esfuerzos o desplazamientos terminan siendo no redituables en términos energéticos para la población (Laguens y Bonnin 2009). La presión creciente sobre los recursos hacia fines del Holoceno tardío y momentos previos a la llegada de los españoles, así como un ambiente circunscripto dado por el aumento demográfico (Laguens 1999) pudo ver favorecida la intensificación de algunas prácticas como la agricultura o la recolección. Según la evidencia arqueológica, en las región de las Sierras Centrales en momentos previos a la conquista española, pudieron haber confluido una alta densidad poblacional, con tecnología tradicional, de poca inversión y cultivo sin riego, junto con estrategias de caza y recolección (Laguens 1999), en un medio en deterioro que veía disminuida su oferta de recursos, y su potencial para el mantenimiento de las poblaciones, tanto humanas como naturales (animales y vegetales), coincidiendo con condiciones climáticas y ambientales de mayor aridez (Cioccale 1999).

Esta situación sugiere un desequilibrio entre el tamaño de la población y el potencial del ambiente: Laguens y Bonnin (2009) han propuesto que en un escenario como el mencionado, la estrategia de subsistencia más plausible de mantener e intensificar fue la de la caza y la recolección. Si consideramos algunas evidencias del registro arqueológico, parecería que la estrategia que más se efectivizó fue la recolectora: en estos momentos se observa mayor inversión en estructuras de almacenamiento ${ }^{5}$, lo cual podría estar indicando estrategias de previsibilidad ante un período crítico que habría comenzado hacia el siglo XVI de la era cristiana, resultado de factores internos a las sociedades asentadas en la región -crecimiento demográfico, cambios ambientales, conflictos- como externos -conquista española-, lo cual habría generado mayor competitividad por los territorios y los recursos.

En este trabajo consideramos que la población en su conjunto presenció eventos de estrés vinculados a la combinación de los factores citados arriba- aumento demográfico, reducción en la disponibilidad de recursos, cambios en la alimentación-, pero según nuestro registro habrían sido los individuos masculinos quienes sufrieron los eventos de estrés más fuertes, en momentos previos

\footnotetext{
${ }^{5}$ En el sitio El Ranchito ubicado, en la región Noroeste se han localizado grandes sitios con pozos subterráneos en forma de campana denominados comúnmente "botijas", en donde se han recuperado restos carbonizados de semillas que no pudieron ser identificadas con seguridad, pero por morfología posiblemente corresponda a algún tipo de acacia, muy probablemente Prosopis sp. (Laguens y Bonnín 1987). En sitios ubicados en al región Noreste también se han localizado concentraciones de estas estructuras de almacenamiento (Frenguelli y De Aparicio 1932), en algunos casos asociadas a entierros humanos (Fabra et al. 2008).
} 
a la conquista española. En este escenario, es plausible que la reducción de la disponibilidad de recursos de origen animal, y el aumento de los recursos vegetales -obtenidos a través de la recolección y/o agriculturahubieran generado una reducción en la variabilidad de alimentos consumidos, y esta reducción hubiera afectado mayormente a individuos de la región Noreste, y a los masculinos de la región de Traslasierra.

Por otra parte, se observaron diferencias en la representatividad de esta patología en las distintas categorías sexuales y etarias de la población analizada, siendo algunas diferencias estadísticamente significativas.

Con respecto a la relación entre la presencia de hipoplasias y el sexo de los individuos, los resultados son variables. Hombres y mujeres pueden diferir en cuanto a la vulnerabilidad al estrés ambiental, y su dentición puede registrar niveles diferentes de afectación, así también la exposición a diferentes niveles de estrés como resultado de las preferencias culturales para hombres o mujeres en la niñez puede variar (Guatelli-Steinberg y Lukacs 1999; King et al. 2005).

En las poblaciones analizadas en este estudio, al evaluar la muestra en su conjunto se observó un incremento en los porcentajes de representatividad de esta patología en el Holoceno tardío final, siendo además esta diferencia estadísticamente significativa en comparación con momentos previos. Individuos masculinos como femeninos presentaron esta patología, siendo más frecuente en estos últimos. Al evaluar la prevalencia regional de esta patología, considerando además el sexo y la cronología, los resultados fueron significativos para las regiones Noreste y Traslasierra, donde los individuos masculinos, adultos jóvenes y medios exhibieron mayor frecuencia de esta condición.

Interpretamos que la mayor presencia de hipoplasias en los individuos masculinos de la región de Traslasierra puede deberse a dos causas: a) acceso diferencial a los recursos alimenticios, o b) niveles distintos de exposición al estrés, resultando en una mayor mortalidad de la población femenina, y por ende, una mayor frecuencia de hipoplasia dental entre los individuos masculinos, quienes habrían sobrevivido a estos eventos de estrés. Lamentablemente la muestra analizada corresponde sólo a individuos adultos, hecho que nos impide realizar un perfil de mortalidad y poder estimar si los individuos femeninos efectivamente morían a edades tempranas. Sin embargo, hay que destacar que los individuos femeninos también presentaron altas prevalencias de hipoplasias en el Holoceno tardío, lo cual sugiere que la población en general estuvo expuesta a situaciones de estrés, lo cual no invalida el patrón observado en particular para la región de Traslasierra. Si bien la evidencia tanto arqueológica como etnohistórica es insuficiente en esta región sobre este punto, consideramos como una posibilidad que se haya producido una reducción en la disponibilidad de alimentos, y quizás una mayor competencia por los recursos, lo cual habría reducido la oferta alimenticia, derivando posiblemente en un estrés nutricional, principalmente para los individuos masculinos.

En cuanto a la presencia de hipoplasias en la región Noreste, se observaron diferencias estadísticamente significativas al comparar la prevalencia de esta patología entre momentos iniciales y finales del Holoceno tardío. Consideramos que en esta región pudieron haber confluido varios de los factores previamente considerados, entre ellos la reducción en la disponibilidad de los recursos alimenticios. Recordemos que el cambio climático y ambiental conocido como la Pequeña Edad de Hielo (Ciocalle 1999) produjo un deterioro climático a partir del siglo XIV de la era cristiana, hacia condiciones más áridas y frías que las observadas en el presente; particularmente en esta región este fenómeno se habría traducido en una disminución de los principales cursos de agua, así como una reducción de los niveles en el principal espejo de agua de la región -la Laguna Mar Chiquita (Piovano et al. 2002)- lo cual podría haber afectado la oferta de recursos alimenticios tanto acuáticos como los obtenidos del ambiente circundante a la laguna y del bosque chaqueño. En coincidencia con estos cambios ambientales, la introducción de cultígenos como el maíz podría haber originado eventos de estrés que habrían repercutido negativamente en la salud de las poblaciones que habitaron esta región.

En cuanto a la relación entre edad de muerte y la presencia de hipoplasias, en la muestra analizada se presentó cierta variabilidad en cuanto a las prevalencias, al considerar la muestra en su conjunto, o la prevalencia combinando la información regional o cronológica. Si tenemos en cuenta el total de la muestra, esta patología se mostró como más prevalente en individuos jóvenes y medios. Pero al considerar las regiones, vemos que en Traslasierra y Noroeste esta patología es más frecuente en individuos jóvenes y medios, mientras que en las regiones de Llanura y Sierras Chicas estaría más presente en adultos mayores. Por último, al considerar la información cronológica, vemos que en momentos iniciales del Holoceno los adultos medios y mayores tendrían mayores valores en Traslasierra y Sierras Chicas, mientras que hacia el tardío final los adultos jóvenes y medios de todas las regiones presentarían esta patología.

Si consideramos en conjunto la información cronológica y arqueológica regional, observamos que hacia momentos finales del Holoceno tardío los individuos que mayor frecuencia de hipoplasias presentan son los adultos jóvenes y medios en todas las regiones, en contraposición con momentos iniciales en donde sólo los adultos medios y mayores de las regiones de Traslasierra y Sierras Chicas presentan esta patología. Esta mayor incidencia en los individuos jóvenes y medios hacia momentos finales 
del Holoceno tardío puede estar relacionada con a) el desgaste dental, que progresivamente aumenta con la edad del individuo, y por lo tanto pueda generar una dificultad en el registro y visualización de este indicador en individuos mayores, ó b) que los individuos adultos jóvenes que registran mayor frecuencia de prevalencias sean los individuos que hayan sobrevivido a mayores eventos de estrés y por lo tanto, sean los más fuertes o resistentes (Wood et al. 1992), o por el contrario, que los individuos adultos mayores hayan sido quienes sufrieron menores eventos de estrés y por lo tanto hayan sobrevivido hasta edades más avanzadas.

El desgaste dental es una patología que en ocasiones puede influir en la cuantificación y caracterización de los defectos y patologías dentales. Los niveles altos de desgaste remueven los elementos que conforman la corona, perdiéndose así gran cantidad de datos (King et al. 2005). Sin embargo, debe tenerse en cuenta que la mayoría de los defectos hipoplásticos se producen en el tercio cervical y medio de la corona, por lo tanto sólo en los casos en que el desgaste dental es tan avanzado que ha llegado a afectar la raíz del diente, se produce pérdida de la información. En este trabajo, si bien no descartamos que esta variable haya influido en el registro de datos -ya que hacia momentos finales del Holoceno tardío el grado de desgaste dental no es tan avanzado como el registrado en los momentos iniciales-, consideramos que la diferencia existente entre los individuos adultos mayores y jóvenes puede deberse principalmente a factores relacionados con la salud y mortalidad diferencial.

La tendencia hacia la disminución de las prevalencias de hipoplasias al aumentar la edad de muerte es un patrón identificado en muestras bioarqueológicas de diferentes partes del mundo con variados patrones de subsistencia (Buikstra y Cook 1980; Goodman y Armelagos 1988; Larsen 1997; Powell 1988). La relación entre la frecuencia de hipoplasias y la edad de los individuos permite en este caso desechar la hipótesis de que los individuos con mayor prevalencia de hipoplasias hayan sido los más fuertes, ya que disminuye con la edad. Por otra parte, no se han registrado ejemplos en poblaciones etnográficas en las cuales un grupo aventajado haya presentado más lesiones que uno en desventaja (Goodman 1993; May et al. 1993). Por el contrario, las hipoplasias prevalecen en condiciones de alta exposición a las enfermedades, y bajo acceso a los recursos alimentarios y de salud básicos. Por lo tanto, consideramos que los individuos adultos jóvenes y medios que presentaron las mayores frecuencias de este indicador fueron quienes estuvieron expuestos a mayores o más graves eventos de estrés, y por lo tanto, los menos aventajados de la población, por lo que no han logrado llegar a la vejez. Situaciones similares han sido registradas por Luna (2008) para una muestra de cazadores-recolectores de la región pampeana, en donde también observa una tendencia hacia la disminución de los defectos hipoplásticos con el avance de la edad, principalmente en los individuos masculinos, y mayores valores de hipoplasias para individuos femeninos. Estos individuos habrían sobrevivido a la adolescencia, pero producto de situaciones de estrés sufridos durante la niñez, no logran superar la edad reproductiva. Para el autor, estas diferencias registradas podrían estar indicando diferencias sexuales en lo que respecta a situaciones de estrés sufridas por los individuos que alcanzaron la adultez (Luna 2008).

En síntesis, algunos de los indicadores analizados, particularmente las líneas de hipoplasia, estarían aportando elementos para pensar que el desequilibrio entre el tamaño de la población y la disponibilidad del ambiente habría impactado en la calidad de vida de estas poblaciones, generando un deterioro en las condiciones generales de salud, principalmente en los individuos adultos jóvenes y medios de toda la región estudiada, pero con mayor intensidad en las regiones de Noreste y en individuos masculinos de Traslasierra

Córdoba, 30 de Mayo de 2011

\section{Agradecimientos}

Este trabajo deriva de la tesis de licenciatura de una de las autoras (CVG), y forma parte del proyecto "Patrones espaciales de variabilidad biológica y estilos de vida en poblaciones de la región central de Argentina durante el Holoceno", dirigido por Mariana Fabra (PIP 2011-2013 -114 20100100164). Las autoras desean agradecer a los museos públicos que facilitaron no sólo el acceso a sus colecciones, sino la colaboración prestada para la realización de trabajos de rescate arqueológico: Museo de Antropología (FFyH, UNC), Museo Histórico Municipal de La Para (La Para, Córdoba), Museo de la región de Ansenuza "Aníbal Montes" (Miramar, Córdoba), Museo Arqueológico Provincial "Aníbal Montes" (Río Segundo, Córdoba). Asimismo, agradecen las sugerencias y comentarios realizados por los evaluadores, los cuales ayudaron a mejorar sensiblemente el trabajo. La realización del mapa que completa la Figura 1 estuvo a cargo de Paola Franco.

\section{Bibliografía}

Barrientos, G. 1999. Metodología de análisis de hipoplasias del esmalte dental aplicada al estudio de poblaciones prehispánicas del Sudeste de la Región Pampeana, Revista Argentina de Antropología Biológica 2: 307-322.

Bonnin, M. y A. G.Laguens. 2000. Esteros y algarrobales. Las sociedades de las Sierras Centrales y la llanura santiagueña. M. N. Tarragó, (ed.), Nueva Historia Argentina, Tomo I Los pueblos originarios y la conquista, pp. 149-186, Editorial Sudamericana, Buenos Aires. 
Bonnin, M. y A. G. Laguens, S. Díaz. 1987. Ambiente actual y pasado de la cuenca del río Copacabana (Departamento Ischilín, Provincia de Córdoba, Argentina). Publicaciones del Instituto de Antropología, Nueva Época, XLV: 159-201.

Bonofiglio, M. 2004. Cosme, un sitio en el piedemonte (Riberas del Río Xanaes). Actas Cuartas Jornadas de Arqueología y etnohistoria del centro del País. Universidad Nacional de Río Cuarto. Facultad de Ciencias Humanas. Volumen II, pag.41-53

Bonofiglio, M. 2009. Arqueología de la Zona lacustre de Córdoba. Un modelo para Armar, Las sociedades de los paisajes áridos del centro- oeste Argentino, Volumen I, pag. 83-100

Buikstra, J.E., y D.C. Cook. 1980. Paleopathology: An American Account. Annual Review of Anthropology 9: 433-470.

Buikstra, J. y D. Ubelaker (eds.) 1994. Standards for Data Collection from Human Skeletal Remains. Field Museum of Natural History, Arkansas Archaeological Survey Research Series, No 44.

Capitanelli, R. G. 1979. Clima, en Geografía física de la Provincia de Córdoba, J. B. Vázquez, R.A. Miatello y M.E. Roqué (eds), Ed. Boldt, Buenos Aires, pp. 47-139

Carignano, C. 1997. El Holoceno en la Provincia de Córdoba (Argentina), Revista del Instituto de Geología y Minería, Vol. 11 (2): 1-21

Cioccale, M.A. 1999. Climatic fluctuation in the Central Region of Argentina in the last 1000 years. Quaternary International 62 (1): 35-47.

Cohen, M.N. y G.J. Armelagos. 1984. Paleopathology at the Origins of Agriculture. New York: Academic Press.

Fabra, M. y C.V. González. 2008. Análisis de bioindicadores dietarios en poblaciones prehispánicas del Centro de Argentina en el Holoceno Tardío. ArqueoWeb, Revista sobre Arqueología en Internet 10 (1), Junio-Julio. http:// www.ucm.es/info/arqueoweb/pdf/10/fabragonzalez.pdf

Fabra, M. y C.V. González. 2011. First approaches to the study of diet and oral health of populations that inhabited southern region of Sierras Pampeanas (Argentina) during late Holocene. Homo, Journal of Comparative Human Biology. En evaluación

Fabra, M., M.S. Salega y C.V. González. 2009. Comportamiento mortuorio en poblaciones prehispánicas de la región austral de las Sierras Pampeanas durante el Holoceno. Revista Arqueología 15:165-186.
Fabra, M., M.S. Salega, C.V. González, R. Smeding y E. Pautassi .2008. Arqueología de rescate en la costa sur de la Laguna Mar Chiquita: sitio arqueológico El Diquecito. Memorias del Pueblo: Revista del Museo Histórico Municipal La Para 8 (8):37-46.

Frenguelli, J. y F. De Aparicio. 1932 Excursión a la Laguna de Mar Chiquita (Provincia de Córdoba). Publicaciones del Museo Antropológico y Etnográfico de la Facultad de Filosofía y Letras, serie A, II: 121-166

García Guraieb, S. 2004. Salud y enfermedad en cazadores-recolectores del Holoceno tardío en el Lago Salitroso (Santa Cruz"). Tesis de Licenciatura en Ciencias Antropológicas (orientación en Arqueología). Facultad de Filosofía y Letras, Universidad de Buenos Aires. Ms

García Guraieb, S. 2006. Salud y enfermedad en cazadores-recolectores del Holoceno tardío en la cuenca del Lago Salitroso (Santa Cruz). Intersecciones en Antropología 7: 37-48.

González, A.R. y J.A. Pérez. 2007. Argentina Indígena. Vísperas de la conquista. Capitulo 7, pp. 117-123, Editorial Paidos, Buenos Aires.

González, C.V. 2011. “Dieta y salud oral de las poblaciones prehispánicas de la región austral de las Sierras Pampeanas: aportes desde la Antropología Dental". Tesis de Licenciatura en Historia (orientación en Arqueología y Etnohistoria), Facultad de Filosofía y Humanidades, Universidad Nacional de Córdoba. Ms

Goodman, A.H., G. J. Armelagos y J.C. Rose. 1980. Enamel hypoplasias as indicators of stress in three prehistoric populations from Illinois, Human Biology 52: 512.528.

Goodman A.H. y G.J. Armelagos. 1985. Factors affecting the distribution of enamel hypoplasias within the human permanent dentition. American Journal of Physical Anthropology 68: 479-493.

Goodman, A. y J. Rose. 1991. Dental enamel hypoplasias as indicators of nutritional status, en Advances in dental anthropology Kelley, M. y C. Larsen (eds.), pp 279-294. Wiley-Liss. Nueva York

Goodman, A.H. y G. Armelagos. 1988. Childhood stress and decreased longevity in a prehistoric population, American Anthropologist 90: 936- 944.

Goodman, A.H. 1993. On the interpretation of Health from Skeletal Remains, Current Anthropology 34: 281288.

Guatelli-Steinberg D. y J.R. Lukacs. 1999. Interpreting sex differences in enamel hypoplasia in human and nonhuman primates: developmental, environmental, and 
cultural considerations. Yearbook Physical Anthropology 42:73-126.

Hillson, S. 1986. Teeth. Cambridge Manuals in Archaeology Cambridge University Press. Cambridge.

Hillson, S. 1996. Dental Anthropology. Cambridge University Press. Cambridge.

Hillson, S. 2000. Dental pathology, en Biological anthropology of the human skeleton, M. Katzemberg, M. y S. Saunders (eds.), 249-286. Wiley-Liss. Nueva York.

Huss-Ashmore, R., Goodman, A. y G. Armelagos. 1982. Nutritional inference from paleopathology. M. Schiffer (ed.), Advances in Archaeological Method and Theory 5: 395-474.

Iriondo, M., 1999. Climatic changes in the South American plains: records of a continent scale oscillation. Quaternary International 57/58: 93-112.

Keenleyside A. 1998. Skeletal evidence of health and disease in pre-contact Alaskan Eskimos and Aleuts, American Journal of Physical Anthropology 107:51-70.

King, T., L.T. Humphrey y S. Hillson. 2005. Linear Enamel Hypoplasias as Indicators of Systemic Physiological Stress: Evidence from Two Known Age-at-Death and Sex Populations from Postmedieval London, American Journal of Physical Anthropology 128: 547-559

Laguens, A. 1993. Locational structure of archaeological underground storage pits in northwest Córdoba, Argentina. Rev. do Mus. de Arq. e Etnol., S. Paulo 3, 17-33.

Laguens, A. 1999. Arqueología del contacto hispanoindigena. Un estudio de cambios y continuidades en las Sierras Centrales de Argentina. BAR International Series 801, Oxford.

Laguens, A. y M. Bonnin. 1987. Espacio, paisaje y recursos. Estrategias indígenas alternativas y complementarias en la cuenca del río Copacabana (Dto. Ischilín, Córdoba, Arg.). Sitio El Ranchito: 1000 a.C.-1600 d.C. Publicaciones del Instituto de Antropología, XLV (1985), Córdoba.

Laguens, A.G. y M. Bonnin. 2009. Sociedades indígenas de las Sierras Centrales. Arqueología de Córdoba y San Luis. Editorial Universidad Nacional de Córdoba, Córdoba, primera edición, pp.452, ISBN 978-950-33-0738-0.

Laguens, A.G., M. Giesso, M. Bonnin y M. Glascock. 2007. Interacciones a larga distancia entre cazadoresrecolectores del Holoceno Medio en Intihuasi, San Luis, Argentina. Debates Actuales en Arqueología y Etnohistoria. Publicación de las $V$ y VI Jornadas de
Investigadores en Etnohistoria del Centro-Oeste del país. Foro Pueblos originarios-arqueólogos. Universidad Nacional de Río Cuarto. Pp. 135-142.

Laguens, A., Fabra M., Macedos Dos Santos G. y D. Demarchi. 2009. Paleodietary inferences based on isotopic data for pre-hispanic populations of the Central Mountains of Argentina. International Journal of Osteoarchaeology. 19: 237-249

Langsjoen, O. 1998 Diseases of the dentition. A.C. Aufderheide y C. Rodríguez-Mann (eds) The Cambridge encyclopedia of human paleopathology, Cambridge University Press, 393-412.

Larsen, C.S. 1987. Bioarchaeological interpretation of subsistence economy and behavior from human skeletal remains. Advances in Archaeological Method and Theory, 10:339-445

Larsen, C.S. 1995. Biological changes in human populations with agriculture. Annual Review of Anthropology 24: 185-213.

Larsen C.S 1997. Bioarchaeology: Interpreting behavior from human skeleton. Cambridge University Press. Cambridge. UK.

Leonardi, P.A., 1961. Contribución al conocimiento de la estratigrafía y paleontología de la Pampa de Olaen. Tesis Doctoral. FCEFyN-UNC. Ms

Lukacs, J.R. 1989. Dental Paleopathology: Methods for reconstructing dietary patterns, $M$. Iscan y K. Kennedy (eds.), Reconstruction of life from the skeleton. pp. 261286. New York.

Lukacs, J.R. 1995. The 'caries correction factor': a new method of calibrating dental caries rates to compensate for ante-mortem loss of teeth. International Journal Osteoarchaelogy 5:151-156.

Luna, L. 2008. Estructura demográfica, estilo de vida y relaciones biológicas de cazadores recolectores en un ambiente de desierto. Sitio Chenque I (Parque Nacional Lihué Calel, provincia de La Pampa, Argentina), ISBN 978 140730366 6, BAR International Series 1886, Oxford.

May, R., A. Goodman y R. Meindl.1993. Response to bone and enamel formation to nutritional supplementation and morbidity among malnourished Guatemalan children. American Journal of Physical Anthropology 92: 37-51.

López, L. 2007. La Producción de Alimentos en las sociedades prehispánicas tardías de Córdoba. Comechingonia virtual Revista Electrónica de Arqueología. Número 1: 12 -31. http//: www.comechingonia.com. (Última consulta: 10/12/2010) 
Medina, M., y Pastor S. 2006. Chacras dispersas. Una aproximación etnográfica y arqueológica al estudio de la agricultura prehispánica en la región serrana de Córdoba Comechingonia 9: 103-121.

Medina, M., López, L y Berberian, E. 2009. Agricultura y recolección en el tardío prehispánico de las Sierras de Cordoba (Argentina). El registro arqueobotánico de C. Pun.39. Arqueología 15:217-229

Ortner, D. 2003. Identification of pathological conditions in human skeletal remains. Academic Press. Florida.

Pastor, S. 2006. "Arqueología del Valle de Salsacate y pampas de altura adyacentes (Sierras Centrales de Argentina). Una aproximación a los procesos sociales del período prehispánico tardío (900-1573 d.C.)". Tesis doctoral inédita. Universidad Nacional de La Plata.

Piovano, E., S. Damatto Moreira y D. Ariztegui. 2002. Recent environmental changes in Laguna Mar Chiquita (Central Argentina): A sedimentary model for a highly variable saline lake. Sedimentology 49, 1371-1384

Powell, M. 1988. Status and health in prehistory. Smithsonian Institution Press, Washington D.C.
Scott, G.R. y C.G. Turner II. 1988. Dental anthropology. Annual Review of Anthropology 17:99-126.

Smith, H.B. 1984. Patterns of molar wear in huntergatherers and agriculturalists. American Journal of Physical Anthropology, 15: 315-326.

Starling, A.P. y J.T. Stock. 2007. Dental Indicators of Health and Stress in Early Egyptian and Nubian Agriculturalists: A Difficult Transition and Gradual Recovery. American Journal of Physical Anthropology, 134: 520-528

Turner, C. 1979. Dental anthropological indications of agriculture among the Jomon people of central Japan, American Journal of Physical Anthropology, 51: 619-636.

Walker, A.C., H.N. Hoeck y L. Perez. 1978. Microwear of mammalian teeth as an indicator of diet, Science 201: 908-910.

Wood, J.W., G.R. Millner, H.C. Harpending, y K.M. Weiss. 1992. The osteological Paradox. Problems of inferring prehistoric health from skeletal samples, Current Anthropology 33 (4): 343-369. 